\title{
Tutela penal nicaragüense de la Propiedad Industrial con énfasis en el delito de fraude sobre patente, modelo de utilidad o diseño industrial \\ Nicaraguan Criminal protection of the Industrial property, with emphasis on the crime of patent fraud, utility model or industrial design
}

\author{
Jessica Alexandra Flores Páiz ${ }^{1}$ \\ Universidad Politécnica de Nicaragua
}

\begin{abstract}
RESUMEN
El artículo se centró en analizar un mecanismo de tutela, desde la norma jurídico penal sustantiva, con la que cuentan los titulares de bienes inmateriales, particularmente, los titulares de patentes de invención, modelos de utilidad y de diseños industriales, como medida coercitiva de mayor rigurosidad para perseguir y castigar a los infractores de sus derechos exclusivos con penas que incluye la privación de libertad, para ello se utilizó en la elaboración de este trabajo investigativo el método teórico-documental a través de instrumentos como la exploración y análisis documental de una serie de fuentes primarias y secundarias del conocimiento, mediante lo cual se evidenció por un lado que los delitos contra la Propiedad Industrial presentan características similares que son perfectamente deducibles del propio precepto normativo y por otro lado, se determinó la protección de la Propiedad Industrial desde la norma jurídico penal sustantiva, como una herramienta a conocer y aplicar por los titulares de Derechos de Propiedad Industrial en la resolución de sus controversias en esta materia.
\end{abstract}

Palabras clave: Derecho Penal, Invención, Propiedad Industrial, Patente, Registro

\begin{abstract}
The article was focused on analyzing a mechanism of guardianship, from the substantive criminal legal rule, which has holders of intangible property, particular holders of patents of inventions, utility models and industrial designs, such as more rigorous coercive measures to prosecute and punish violators of their exclusive rights with penalties including privation of freedom, to do this research it was used theoretical and documentary method by mean of explorations and documentary analysis of primary and secondary sources of knowledge, through it was evidenced in one hand crime against industrial property have similar characteristics and are perfectly deductible from the very normative provision and on the other hand, the protection of Industrial Property was determined from the substantive criminal legal rule, as a tool to be known and applied by the holders of Industrial Property Rights in the resolution of their disputes in this matter.
\end{abstract}

Keyword Criminal Law, Invention, Industrial Property, Patent, Registration

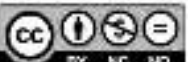

\footnotetext{
${ }^{1}$ Abogada y Notaria Pública de la República de Nicaragua. Docente de Derecho de Propiedad Intelectual y Propiedad Industrial en UPOLI Managua. Licenciada en Comunicación Social por la UCA-Managua (2012). Licenciada en Derecho por la UNAN-León (2015). Master en Derecho Penal y Derecho Procesal Penal por la UNAN-León (2019)
} 


\section{Introducción}

El auge de las creaciones intelectuales especialmente de aplicación industrial como actividad meramente empresarial, así como las manifestaciones propias de la libre concurrencia en el mercado que ha incrementado la rivalidad entre las empresas que convergen en la oferta de productos y servicios a nivel nacional como Internacional, y la necesidad de sus creadores o titulares de proteger tales bienes inmateriales o innovaciones comercializables ha puesto de manifiesto la importancia del acto del registro que le confiere al titular un monopolio de explotación por un tiempo determinado, asimismo una serie de Derechos de exclusividad sobre su propiedad, entre ellos la oportunidad de perseguir y castigar a quienes violenten sus Derechos ante las autoridades competentes.

De tal manera que, para constituir tales bienes inmateriales como Propiedad Industrial mediante el acto de registro, en principio debemos entender qué es el Derecho de Propiedad Industrial.

La Propiedad Industrial es el conjunto de derechos que sirven para proteger a las personas físicas o morales que desean reservar sus creaciones (patentes, modelos de utilidad, diseños industriales), distinguir sus productos o servicios de otros de su misma especie o clase (marcas, denominaciones de origen), proteger la originalidad de sus avisos comercial conservar la privacidad de sus secretos industriales o comerciales, distinguir la identidad de sus establecimientos comerciales respecto de otros dedicados al mismo giro, proteger el procedimiento para la obtención de nuevas variedades vegetales y de biotecnología, y que les proporcione también derecho a enajenar dichos bienes inmateriales y a perseguir a los que infrinjan tales derechos ante las autoridades competentes. (Viñamata, 2007, p. 181 y s)

Por tanto, la Propiedad Industrial que es una de las ramas que conforman la Propiedad Intelectual no podría considerarse bajo ese título en tanto no sea protegida por la entidad correspondiente a la luz de un vasto marco jurídico sobre la materia, en ese sentido Sherwood (1995) manifiesta: “Cuando los productos de la mente reciben protección pública, se puede usar apropiadamente el concepto de propiedad intelectual. Constituye en algún sentido equívoco hablar de omitir proteger la propiedad intelectual. Si no hay protección, no hay propiedad intelectual" (p.24).

Al respecto, nuestro ordenamiento jurídico nacional regula y protege el Derecho de Propiedad Industrial a través de las siguientes leyes especiales: Ley No. 380 Ley de Marcas y otros signos distintivos, Ley No. 354 Ley de Patentes de Invención, modelo de utilidad y diseños industriales, Ley No. 318 Ley de Protección de las obtenciones vegetales, Ley No. 324 Ley de Protección a los esquemas de trazados de circuitos integrados, y sus respectivos 
reglamentos $^{2}$; todas ellas surgen como producto de la modernización y mejoras legislativas en cumplimiento de los Acuerdos o Tratados y Convenios Internacionales suscritos por Nicaragua, así como el cumplimiento de los Acuerdos ratificados a nivel centroamericano con el resto de países de la Región, apuntando a la regulación y protección armonizada e integral de la Propiedad Industrial en miras del desarrollo comercial a nivel Centroamericano y mundial, asimismo en respuesta de las situaciones acaecidas producto de la inminente era electrónica o digital cuyas esferas de actuación trasciende la territorialidad nacional, entre los Instrumentos que podemos mencionar se encuentran el Convenio de la Unión de París para la protección de la Propiedad Industrial del año 1883 que fue uno de los primeros Tratados en el cual se reconoce la importancia de la Propiedad Intelectual a nivel mundial y que es uno de los Instrumentos administrados por la Organización Mundial de la Propiedad Intelectual OMPI, asimismo los Acuerdos sobre los Derechos de Propiedad Intelectual relacionados con el Comercio ADPIC incorporados en la suscripción del Acuerdo de la creación de la Organización Mundial del Comercio OMC de 1994.

Sin embargo, la trascendencia de la Propiedad Industrial en el ámbito económico o empresarial en Nicaragua y a nivel mundial, así como el aparejado incremento de usos comerciales ilícitos o competencia desleal por parte de terceros, motivó que se estableciera un mecanismo de tutela más efectivo y riguroso para prevenir, frenar y castigar a quienes violentaran los Derechos exclusivos de los titulares registrales de Propiedad Industrial, de tal manera el legislador reformó las cláusulas penales establecidas en las leyes especiales antes mencionadas incluyendo en el código penal nicaragüense del 2008 los delitos contra la Propiedad Industrial, los cuales se encuentran regulados dentro del título VI sobre los Delitos contra el patrimonio y el orden socioeconómico.

Los Delitos contra la Propiedad Industrial se encuentran recogidos en el Capítulo X, los cuales se desarrollan de la siguiente manera: art. 252 CP Fraude sobre patente, modelo de utilidad o diseño industrial, art. Art. 253 CP Violación a los derechos de patente, modelo de utilidad o diseño industrial, art. $254 \mathrm{CP}$ Delitos contra el derecho de obtentor, art. $255 \mathrm{CP}$ Utilización comercial ilícita de marcas y otros signos distintivos, art. 256 CP Violación de derechos derivados de la titularidad de esquemas de trazado o topografías de circuitos integrados, art. 257 CP Publicación de sentencias.

\section{Elementos típicos comunes en los delitos contra la propiedad industrial}

De los tipos penales puntualizados en el párrafo que antecede se desprenden de manera expresa o tácita exigencias típicas comunes de los cuales podemos mencionar: fines comerciales o industriales, previa inscripción registral del título, conocimiento del registro por parte del infractor y falta de consentimiento o autorización del titular del Derecho registrado, y que paso a citar a continuación:

\footnotetext{
${ }^{2}$ Hasta la fecha se han efectuado algunas reformas y adiciones parciales a las leyes y reglamentos en mención.
} 
2.1) Fines comerciales o industriales: De los presupuestos típicos expresados en estos delitos se deduce que estos actos descritos se introducen al tráfico mercantil. El legislador incluye verbos rectores comunes para describir el núcleo de cada conducta típica en estos delitos como son: venta, distribución, importación, exportación, comercialización, además de establecer la finalidad comercial directamente en el art. 255 CP Utilización comercial ilícita de marcas y otros signos distintivos. Inciso c) La utilización con fines comerciales de envases, envolturas, o embalajes que lleven una marca registrada o signo distintivo [...].

Por su parte la doctrina española refiere que "el fin industrial o el destino a la explotación o introducción en el comercio, ámbito o tráfico mercantil de los elementos u objetos amparados por derechos de propiedad industrial resulta, pues, condición de la intervención penal tanto como los es de la tutela mercantil y administrativa” (Tirado, 2016, p.12).

2.2) Previa inscripción registral del título: La protección penal se otorga únicamente a los títulos de Propiedad Industrial debidamente inscritos en el registro de la Propiedad Intelectual RPI dependencia del Ministerio de Fomento, Industria y Comercio MIFICNicaragua conforme a lo establecido en la ley de la materia. A como Mapelli (2001) refiere respecto a lo dispuesto en la legislación penal española sobre esta materia: "no existirían delitos contra la propiedad industrial ni su protección penal sin el requisito registral que le confiere ese carácter" (p. 126).

2.3) Conocimiento del Registro por parte del infractor (sujeto activo): Este requisito exige que el autor del delito actúe con conocimiento del registro del título de Propiedad Industrial lo cual podríamos suponerlo de dos maneras: primero, por la publicidad que se deriva del propio acto del registro, y segundo, por lo descrito en las conductas típicas que indican el conocimiento, y el dolo o voluntad, por parte del sujeto activo al realizar los actos prohibidos en la norma penal [...]. (Flores, 2019, p.24)

2.4) Falta de autorización del titular del Derecho registrado: Los tipos penales relativos a la Propiedad Industrial refieren uniformemente y de manera literal que quien realice los actos o conductas típicas sin autorización escrita del titular del derecho comete el ilícito penal, de tal manera que si existiese autorización por parte del propietario entonces la conducta sería atípica. (Flores, 2019, pp.24-26)

\section{Análisis de los elementos del delito art. $252 \mathrm{cp}$ fraude sobre patente, modelo de utilidad o diseño industrial}

En este apartado se analizan los elementos que conforman la estructura y contenido de uno de los delitos relativos a la Propiedad Industrial desde la perspectiva de la Teoría general del delito la cual según manifiesta Luzón (2017) se puede resumir en la siguiente estructura 
básica: Acción, Tipicidad, Antijuricidad y Culpabilidad, "El delito será, pues, la acción típica, antijurídica y culpable" (p. 163). Sin embargo algunos autores añaden un quinto elemento: la punibilidad.

\subsection{Parte positiva del tipo (Elementos Objetivos):}

3.1.1 El bien jurídico protegido en el tipo penal base de esta investigación es el Derecho de uso o explotación exclusiva de la Patente de invención, modelo de utilidad o diseño industrial por parte del titular registral por un tiempo determinado, lo cual se corresponde con la doctrina mayoritaria española, así como con lo establecido en el precepto legal del CP/2008 que literalmente cita que cometerá este delito: "quien sin autorización escrita del titular del Derecho realice cualquiera de los siguientes actos [...]”. Es deducible que el legislador pretende proteger el derecho exclusivo del propietario de este bien inmaterial, y por ende prohibir a terceros el uso de su patente de invención, modelo de utilidad o diseño industrial.

3.1.2 Acción o conducta típica: La acción o conducta típica es la concreta conducta, activa u omisiva, descrita por el tipo penal, y este último es el supuesto de hecho abstracto descrito en la norma jurídico penal, y que se analizo a continuación:

a) Análisis de las conductas típicas:

Partiendo del significado de Fraude que se define en el diccionario de la lengua española de la Real Academia Española RAE en sentido general es la acción contraria a la verdad y la rectitud, o engaño que perjudica a la persona contra quien se comete, analizaremos las conductas típicas que integran los dos apartados del delito Fraude sobre patente, modelo de utilidad o diseño industrial (Art. $252 \mathrm{CP}$ ).

El inciso a) incrimina penalmente la siguiente conducta típica: Hacer parecer como producto patentado, protegido por modelo de utilidad o diseño industrial, aquellos que no lo estén.

A como lo ha definido la RAE se entiende por la palabra "parecer" a tener determinada apariencia o aspecto. De esta definición podemos determinar dos puntos esenciales: uno, que por la acción o conducta típica nos encontramos con un delito de mera conducta activa que no exige un resultado distinto de la misma conducta para consumar el delito, sobre estos delitos Luzón (2017) manifiesta: "En los delitos de mera conducta el tipo sólo requiere una determinada conducta, activa o pasiva, sin necesidad de un ulterior resultado distinto de aquella” (p. 227), y dos, que por el bien jurídico protegido y el modo de afectación del bien jurídico se trata de un delito de lesión, el mismo autor Luzón (2017) refiere: "Los delitos de lesión suponen ya la efectiva lesión o menoscabo del bien jurídico” (p. 232), por tanto con 
este acto o conducta el sujeto activo lesiona el bien jurídico protegido con el solo hecho de dar la apariencia de determinado(s) producto(s) como un producto que ha sido debidamente patentado, protegido por modelo de utilidad o diseño industrial.

El inciso b) incrimina penalmente la siguiente conducta típica: invocar ante tercera persona, sin ser titular de una patente, modelo de utilidad o diseño industrial o sin gozar ya de estos privilegios, como si disfrutara de tal titularidad y privilegios.

Conforme se define en el diccionario de la RAE la palabra invocar proviene del latín invocare que significa llamar en solicitud de ayuda de manera formal o ritual. Asimismo, acogerse a una ley, costumbre, o razón. Partiendo del significado de invocar, se puede deducir que el sujeto activo realiza el acto de invocar o llamar en solicitud de ayuda ante tercera persona mostrándose como si fuera el titular, o de haberlo sido como si aún gozara de tal titularidad con el fin de recibir alguna ventaja exclusiva o especial o de seguir gozando de tales ventajas producto de la concesión del título de patente, modelo de utilidad o diseño industrial.

Por la acción o conducta realizada, al igual que el inciso anterior, se trata de un delito de mera conducta activa que no exige un resultado distinto de la propia conducta, y que lesiona el bien jurídico protegido con la realización del acto de invocar ante tercera persona sin ser titular de una patente, modelo de utilidad o diseño industrial o sin gozar ya de estos privilegios, como si disfrutara de tal titularidad y privilegios.

b) Relación de causalidad e imputación objetiva (relación acción y resultado):

Cabe precisar que la conducta o acción típica para ser penalmente relevante requiere la producción de un resultado surgiendo así la problemática acerca de la relación causal entre acción y resultado, y relación de imputación objetiva entre el resultado y la acción, y siendo que se enmarco a este tipo penal como un delito de mera actividad es necesario comprender respecto de la determinación de la relación de causalidad, a como lo ha manifestado Gimbernat (1991) quien señala:

“... a diferencia de los delitos de resultado, en los delitos de actividad el resultado siempre tiene lugar simultáneamente con la actividad desplegada por el agente, y por ello, la constatación de la relación de causalidad entre acción y modificación del mundo exterior, que en estos delitos, exactamente igual que en los de resultado, es un elemento del tipo [...]" (p. 116).

Por otro lado, en referencia a la determinación de la relación de imputación objetiva Luzón (2017) menciona a un sector de la doctrina que plantea un primer nivel de la imputación objetiva antes de la imputación del resultado que es la imputación de la conducta o 
comportamiento. “... más importante cuantitativamente será la cuestión del encaje de la propia conducta en el fin de la norma típica” (Luzón, 2017, p. 308).

b) Fases de realización de la acción o conducta típica (Iter Criminis):

Respecto a las fases externas de la realización del hecho típico cabe detallar que en el delito que se analiza no se tipifica la fase preparatoria (actos preparatorios punibles: La conspiración, la proposición y la provocación para delinquir establecidos en el art. 31 y 32 $\mathrm{CP})$ ya que se ciñe al sistema de numerus clausus en el que se ha establecido, por regla general, que estos actos preparatorios sólo serán sancionados en los casos especiales expresamente previsto en la ley. Por tanto, interesa conocer la fase ejecutiva compuesta por actos ejecutivos en la que el sujeto da inicio a la ejecución o realización del correspondiente delito, de forma que practica alguno o todos los actos de la conducta típica respectiva.

Del análisis de las conductas típicas que conforman el delito de Fraude sobre patente, modelo de utilidad o diseño industrial, y siendo que es un delito de mera conducta activa, se trata de un tipo penal en el que la consumación existe desde el momento en que se realiza la actividad o conducta típica. Al respecto Orts y González (2004) refieren: "En los delitos de mera actividad y de omisión propia, la consumación existe desde el momento que se realiza toda la conducta o se deja de hacer la conducta prescrita, sin necesidad evidentemente de exigir un resultado, pues éste no lo requiere el tipo" (p. 93).

Sin embargo, se plantea si en el delito que nos ocupa aplican las fases anteriores a la consumación conocidas como formas imperfectas de ejecución, ya que una vez comenzada la ejecución del hecho delictivo, éste puede quedar en fase de tentativa (tentativa inacabada) o frustración (tentativa acabada) si no se realizan todos los actos ejecutivos necesarios. Tales formas imperfectas de ejecución se encuentran reguladas en el art. 28 CP: “... b) Hay frustración cuando la persona, con la voluntad de realizar un delito, practica todos los actos de ejecución que objetivamente deberían producir el resultado, y sin embargo éste no se produce por causas independientes o ajenas a la voluntad del sujeto, c) Hay tentativa cuando el sujeto, con la voluntad de realizar un delito, da principio a su ejecución directamente por hechos exteriores, pero sólo ejecuta parte de los actos que objetivamente pueden producir la consumación, por cualquier causa que no sea el propio y voluntario desistimiento".

Sobre este punto Canizales (2016) afirma: "no se concibe la tentativa ofrustración en los delitos imprudentes o en aquellos delitos que con un solo acto se consuman” (p. 112). Sin embargo, agrega la posibilidad de considerar un delito a nivel de tentativa cuando el delito pueda ser ejecutado por conductas fraccionadas, lo que implica que el delito no signifique una única actividad, y que permita que la ejecución se pueda realizar en varios actos (Canizales, 2016). 
Por su parte, Luzón (2017) coincide con el planteamiento antes expuesto al aseverar que en los delitos de mera conducta no cabe la frustración (tentativa acabada), puesto que en cuanto se lleva a cabo toda la actividad ya se ha consumado el delito, sin embargo difiere respecto a la tentativa (inacabada), ya que según el jurista español en los delitos de mera actividad si cabe, y no sólo en los compuestos de varios actos, sino también en los de un solo acto. Luzón (2017) refiere: “...la tentativa comienza ya cuando el autor se dispone inmediatamente a realizar el primer acto típico" (p. 227).

Tomándose en consideración los planteamientos antes mencionados se puede concluir que en el delito que se analiza no caben las formas imperfectas de ejecución de tentativa y frustración, ya que el delito se consuma con la realización de un solo acto o conducta típica.

3.1.3. Los sujetos del delito: El sujeto activo (autor material o intelectual) en este delito puede ser cualquier persona natural o jurídica, puesto que es un delito común que no requiere cualificación en el autor. Por otro lado, el sujeto pasivo es el titular del bien jurídico protegido, es decir, el titular registral o propietario de la patente de invención, modelo de utilidad o diseño industrial que puede ser una persona natural o jurídica.

a) Autoría y participación (Codelincuencia): Para la determinación del grado de responsabilidad penal de cada uno de los intervinientes en la comisión del hecho delictivo se aplican las reglas generales sobre autoría y participación de conformidad a los arts. 41 al 45 $\mathrm{CP}^{3}$, incluyendo a estas reglas, los particulares que cometan el delito en el seno de una persona jurídica.

En cualquiera de las conductas típicas que componen este delito pueden intervenir uno o varios sujetos (pluralidad de sujetos), por lo que es necesario determinar la contribución de cada uno de ellos en la acción o conducta típica, de tal manera, que para tal fin primero se debe diferenciar entre autores y partícipes tomando como punto de partida lo establecido en nuestro $\mathrm{CP}$, en los artículos mencionados en el párrafo que antecede, y el planteamiento de la Teoría del dominio del hecho, que es la Teoría que acoge nuestro sistema penal nicaragüense.

De acuerdo con esta teoría, autor de un delito es aquel sujeto que tenga el dominio del hecho, aquel que pueda decidir los aspectos esenciales de la ejecución del hecho. Se abandona el criterio objetivo formal para adoptar un criterio material que explique más satisfactoriamente los distintos supuestos de autoría y participación. De acuerdo con esta teoría, el control del hecho se

\footnotetext{
${ }^{3}$ Art. 41 CP: Son penalmente responsables de los delitos y faltas los autores y los partícipes. Autores pueden ser directos, intelectuales, coautores o mediatos. Y son partícipes los inductores, cooperadores necesarios, cómplices $[\ldots]$
} 
realiza a través del dominio de la acción, del dominio de la voluntad o del dominio funcional, según los casos. (Díaz y Martínez, 2016, p. 96)

3.1.4 El objeto material o inmaterial: es la cosa mueble o inmueble sobre la que recae la conducta o acción típica, sería la invención patentada que puede consistir en un nuevo producto o en un nuevo mecanismo o procedimiento, asimismo el modelo de utilidad o diseño industrial este último comprende los dibujos y modelos industriales.

Para un mayor entendimiento de las figuras jurídicas patentes de invención, modelos de utilidad y diseño industrial es necesario conocer su definición legal y doctrinaria.

La ley No. 354 Ley de patentes de invención, modelo de utilidad y diseños industriales en su art. 3 establece los siguientes conceptos: Patente: derecho exclusivo reconocido por el Estado, con respecto a una invención cuyos efectos y alcances están determinados por esta Ley; Modelo de Utilidad: invención constituida por una forma, configuración o disposición de elementos de algún objeto, o de una parte del mismo, que le proporcione algún efecto técnico en su fabricación, funcionamiento o uso; Diseño Industrial: aspecto particular de un producto que resulte de sus características de, entre otros, forma, línea, configuración, color, material u ornamentación, y que comprende todos los dibujos y modelos industriales.

En la doctrina, diversos autores en el estudio de la Propiedad Industrial han desarrollado y conceptualizado tales figuras jurídicas.

Viñamata (2007) define las patentes de la siguiente manera: "Debemos entender la patente como un derecho subjetivo que concede al titular la explotación exclusiva de su invento, con determinadas limitaciones, como la territorialidad y la temporalidad” (p. 232); por su parte, Bendaña (1999) define los modelos de utilidad: "Es toda forma, configuración o disposición de elementos de algún artefacto, herramienta, instrumento, mecanismo u otro objeto, o de alguna parte del mismo, que permita un mejor o diferente funcionamiento, utilización o fabricación del objeto que lo incorpora, o que le proporciona alguna utilidad, ventaja o efecto técnico que antes no tenia" (p. 289); asimismo este último autor Bendaña (1999) define el diseño industrial: "Como un conjunto de líneas o de colores, una forma plástica o una combinación de ambos que, aplicados a un producto industrial o de artesanía, le den una apariencia particular y pueda servir de tipo o modelo para su fabricación [...]" (p. 295). 
3.1.5 El delito de Fraude sobre patente, modelo de utilidad o diseño industrial con elementos normativos del tipo: tomando como base diferenciadora los conceptos de Ley penal en blanco y tipos con elementos normativos, de los cuales en el primer caso algunos autores coinciden que son normas penales estructuralmente incompletas que contienen las consecuencias jurídicas, no así todo o parte del presupuesto o supuesto de hecho, el cual debe completarse mediante otra norma extrapenal a la que se remiten (Luzón, 2017) (Orts y González, 2004), y en el segundo caso, autores como Luzón (2007) refiere: "que en los elementos normativos del tipo hay una remisión parcial interpretativa a una norma extrapenal, o sea para interpretar mediante ésta el alcance de un elemento típico que ya ha establecido la propia ley penal" (p.20), de ello se puede concluir que al igual que en la legislación penal española, y a como Díaz y García Conlledo (2009) en su estudio de los delitos contra la propiedad intelectual e industrial precisa:

"es preferible decir que los tipos que nos ocupan están plagados de elementos con una gran carga normativa y coincidentes con los que recoge la legislación sobre propiedad intelectual e industrial (empezando por el propio concepto de obra literaria, artística o científica, patente o modelo de utilidad, modelo o dibujo industrial o artístico, topografía de un producto semiconductor [...]” ( p. 98).

En definitiva se trata de un delito, como todos los delitos relativos a la Propiedad Industrial, que contiene elementos meramente normativos del tipo ya que es estructuralmente completo, es decir, describe las conductas típicas y sus consecuencias jurídicas, por lo que “... no es precisa una remisión normativa para completar las descripciones típicas, lo que no excluye en absoluto la remisión a las leyes sectoriales con fines meramente interpretativos, esto es, para conocer el significado y alcance de los elementos normativos contenidos en las descripciones típicas" (Flores, 2019, p. 21).

\subsection{Parte positiva del tipo (Elemento Subjetivo)}

3.2.1 Delito puramente doloso: El delito objeto de este estudio presenta únicamente el elemento subjetivo denominado en la doctrina jurídico penal como Dolo, ya que el legislador no estableció en el precepto que se analiza la modalidad imprudente, por tanto, en este punto se rige bajo el sistema que acoge el código penal nicaragüense de numerus clausus, lo cual se encuentra establecido en el art. 22 CP: "Delitos y faltas dolosas e imprudentes: cuando la ley tipifica una conducta lo hace a título de dolo, salvo que expresamente establezca la responsabilidad por imprudencia”.

Por otro lado, si se toma en cuenta la doctrina mayoritaria respecto a la legislación penal española coincidente en que los delitos contra la Propiedad Industrial en general son exclusivamente dolosos y no permiten la incriminación a título de imprudencia, ello por la finalidad comercial o industrial de estos delitos, y en especial porque el CP español al igual 
que el CP nicaragüense, en estos delitos relativos a la Propiedad Industrial, no se castigan estas conductas en su modalidad imprudente. Luzón (2017) en este mismo sentido considera lo siguiente: "los elementos subjetivos del injusto son incompatibles con su comisión imprudente, pues los ánimos específicos implican o presuponen ya el dolo” (p. 319).

3.2.2 Modalidad en dolo directo: Existe dolo directo cuando de forma consciente y querida, la intención del sujeto se dirige directamente al resultado propuesto, bien como un fin o bien asumiendo el resultado como una consecuencia necesaria del acto. (Orts y González, 2004, p. 120), y existiría el dolo eventual cuando el autor se representa como probables las consecuencias de su comportamiento y, no obstante, decide actuar asumiendolas. (Orts y González, 2004, p. 120), por tanto, en base a tales referencias, el delito objeto de este estudio requiere dolo directo ya que en las conductas típicas descritas se evidencia la intencionalidad, además del conocimiento técnico o sobre la materia de parte del sujeto activo, puesto que, haciendo énfasis en el primer inciso, no se puede hacer parecer como producto patentado (aquél que no lo esté) sin que el sujeto conozca todo lo relativo a la patente de invención, título que es otorgado por el Estado mediante un procedimiento complejo, exigente y detallado de registro en la instancia correspondiente y respecto a lo dispuesto en la ley especial de la materia; lo mismo ocurre con los productos protegidos por modelo de utilidad o el diseño industrial.

Por otra parte, el segundo inciso supone dos modalidades: 1) el sujeto activo sin serlo aparente ser propietario legítimo de cualquiera de esos títulos, 2) el sujeto activo aparente seguir siendo titular de tales Derechos cuando ya no gozaré de ellos, en consecuencia, las dos modalidades indican que el sujeto activo tiene pleno conocimiento de la importancia de la registrabilidad, y de los Derechos y privilegios que este acto le otorga al titular. (Flores, 2019, p. 26)

3.2.3 Error de tipo y error de prohibición: (Exclusión del dolo): Sí cabe la posibilidad del error en el delito objeto de este estudio, ya sea error de tipo o error de prohibición; el primero, implica el desconocimiento, por parte del sujeto activo, de los elementos objetivos del tipo penal y la ausencia de voluntad de lesionar el bien jurídico protegido y el segundo, denominado error de prohibición, en el cual sí existe el dolo en la conducta con relación al tipo penal, pero actúa erróneamente en relación a la antijuricidad de la conducta, ya que el sujeto activo cree que su actuar es lícito y permitido por la ley o ni siquiera se plantea la licitud o ilicitud de su conducta. (Canizalez, 2016, pp.98 y 106)

Sin embargo considero que es más probable que se diera el primero, y menos probable el segundo, debido al conocimiento del registro por parte del sujeto activo, así como la cualidad notoria de ser personas que se dedican a la industria o comercio. 


\subsection{Parte negativa del tipo}

\subsubsection{Causas de atipicidad (Contrario a la tipicidad):}

Será atípica la conducta cuando no reúne todas y cada una de las características, requisitos o elementos exigidos en la norma penal y que hemos venido estudiando en este apartado respecto a la estructura y contenido del delito de Fraude sobre patente, modelo de utilidad o diseño industrial, por tanto, la conducta realizada debe encajar o subsumirse a todo lo descrito en la norma. Por ejemplo, será atípica una conducta de Fraude sobre una patente de invención si el titular o los cotitulares de ese título de Propiedad Industrial autorice o conceda, de manera escrita, a tercera persona una licencia de uso.

3.3.2 Causas de justificación de la acción o conducta típica (Ausencia de antijuricidad):

La antijuricidad significa la contrariedad de un hecho o conducta típica con el Derecho en su conjunto. Sobre la antijuricidad Luzón (2017) la clasifica en sentido formal y material:

En sentido formal la antijuricidad es una relación entre la acción o conducta y el Derecho, concretamente la contrariedad a Derecho de la conducta. La acción es antijurídica si es contraria a las normas jurídicas y por tanto es prohibida y desvalorada por las mismas. Y en sentido material Luzón Peña hace referencia a Von Liszt desde quien se suele considerar que el fundamento material de la antijuricidad es la dañosidad o nocividad social de la acción, lo que a su vez sólo sucede si ésta afecta, o sea, lesiona o pone en peligro algún bien jurídico; por ello generalmente se define antijuricidad material como lesión o puesta en peligro de algún bien jurídico. (p. 239)

Entiéndase entonces que las conductas típicas antes analizadas del delito Fraude sobre patente, modelo de utilidad o diseño industrial además de típicas, son antijurídicas, puesto que lesionan un bien jurídico protegido por la norma jurídico penal que es el Derecho de uso o explotación exclusiva de la Patente de invención, modelo de utilidad o diseño industrial por parte del titular registral, y por ende son contrarias al Derecho, sin embargo, pueden ocurrir causas de justificación que excluyen tal antijuricidad. El Jurisconsulto Luzón (2017) explica:

“...Aunque sí hay de entrada afectación del bien jurídico, relevancia jurídica e indicio de injusto, en el caso concreto por haber una colisión de intereses, la ponderación de intereses hace que resulte no desvalorada y por ello se autorice la conducta (en principio) típica si está requerida para salvaguardar intereses jurídicos preponderantes o al menos equivalentes". ( $\mathrm{p}$. 241) 
En el art. 34 CP de las Eximentes de la responsabilidad penal se encuentran establecidas las causas de justificación o supuestos de ausencia de la antijuricidad, que mencionamos a continuación: Legítima defensa, estado de necesidad justificante, y actúe en cumplimiento de un deber jurídico o en el ejercicio legítimo de un derecho, oficio o cargo, tales supuestos solamente pueden ser aplicables si concurren los requisitos exigidos en la norma. Para el delito que nos ocupa, es a mi consideración poco probable o nula la posibilidad de que surja alguna causa o supuesto de justificación.

\subsubsection{Causas de inculpabilidad (Ausencia de culpabilidad):}

Para determinar la culpabilidad de una persona por la comisión de una conducta típica, y antijurídica tenemos que establecer lo siguiente: “... primero su imputabilidad; después atribuirle el hecho bien como doloso o en su defecto como imprudente ${ }^{4}$ y por último, comprobar que le era exigible actuar conforme a Derecho” (Orts y González, 2004, p. 125).

Entiéndase como Imputabilidad a la capacidad de entender, valorar y actuar consecuentemente. Por tanto, en primer lugar, requiere la capacidad de entender y valorar la naturaleza e ilicitud del hecho realizado. En segundo término, precisa también la capacidad de poder actuar según esa apreciación, valoración o comprensión. Así pues, hace referencia a las capacidades físicas, biológicas, psíquicas y psicosociales de una persona en el momento de cometer el hecho. (Orts y González, 2004, p. 119)

Si falta alguna de estas tres etapas entonces no existirá culpabilidad, y por ende no podrá imponerse pena alguna.

Por tanto, es necesario analizar si en la comisión de las conductas típicas del delito que nos ocupa existen causas de inimputabilidad que excluya la imputabilidad y en consecuencia la culpabilidad del autor, entre ellas podemos mencionar: Las anomalías o alteraciones psíquicas; estado de intoxicación plena; alteraciones en la percepción y minoría de edad establecidas en el art. 33 y 34 numeral 1, 2 y 3 del CP.

En la siguiente etapa de análisis resulta necesario determinar una exclusión del dolo por error de tipo o error de prohibición, y el caso fortuito. El error ya fue abordado en el apartado III numeral 3.2.3 de la investigación. Cabe reiterar, que a mi consideración es improbable un caso fortuito y un error de prohibición en el delito de Fraude sobre patente, modelo de utilidad y diseños industriales.

\footnotetext{
${ }^{4}$ Véase Apartado III numeral 3.2 de este documento.
} 
Finalmente, en la tercera etapa de análisis de las causas de inculpabilidad se encuentran las causas de inexigibilidad que son: El estado de necesidad excusante; la fuerza irresistible; el miedo insuperable; exigibilidad genérica y la obediencia debida. Todas ellas contenidas en el art. 34 CP numerales 5, 6, 8, 10 y 11 .

En definitiva, del análisis total de las conductas típicas del delito objeto de este estudio y los supuestos de causas de inculpabilidad, difícilmente podemos aplicar tales supuestos a este delito precisamente por su naturaleza puramente dolosa, excepto en el caso de darse un error de tipo, o tratarse de una minoría de edad en el autor, por ejemplo.

\subsubsection{Punibilidad, Consecuencias jurídicas y Problemas concursales:}

Los vocablos punibles y punibilidad hacen referencia a la pena como consecuencia jurídica. Y con la punibilidad, es decir con la posibilidad de aplicar una pena a quien realiza la conducta típica, antijurídica y culpable, se completa lo que en la doctrina se ha denominado teoría general del delito, puesto que un delito sin punibilidad no tendría razón de ser.

En tal sentido, el delito que se analiza, como el resto de delitos contra la Propiedad Industrial, presenta una penalidad mixta alternativa combinada con una cumulativa: "será sancionado con noventa a trescientos días multas o prisión de uno a dos años e inhabilitación especial por el mismo período para ejercer cargo, profesión, oficio, industria o comercio relacionado con la conducta delictiva...".

Cabe mencionar entre las reglas especiales de aplicación de la pena la posibilidad del Concurso de delitos. En el delito "Fraude sobre patente, modelo de utilidad o diseño industrial" podría concurrir en concurso medial con el delito de estafa cuando el sujeto activo al realizar una de las conductas típicas descritas en el tipo penal que nos ocupa viola otro precepto legal, y esa infracción es un medio necesario para cometer otra infracción, por ende, lesiona más de un bien jurídico tutelado que en el caso de la estafa sería el patrimonio.

A modo de ejemplo, " $\mathrm{X}$ " ofrece a "Y" una cantidad de productos para la salud simulando que su invención le pertenece y ha sido formalmente patentado, con el objetivo de engañar y venderle a "Y" tales productos. En este supuesto, se cometen dos delitos, el fraude sobre patente puesto que " $\mathrm{X}$ " ofrece un producto aparentando que ha sido patentado, y el delito de estafa, al engañar y venderle a "Y" haciéndole creer que son productos con determinadas características y requerimientos legales para su distribución. 


\section{Conclusiones}

A través de este estudio sobre la tutela penal de la Propiedad Industrial y el análisis realizado del delito de Fraude sobre patente, modelo de utilidad o diseño industrial se puede concluir lo siguiente:

1. Se ha logrado mostrar un panorama general acerca del Derecho de Propiedad Industrial como una de las ramas del Derecho de Propiedad Intelectual, y de tal manera introducir el estudio más específico de la tutela que hace nuestro código penal vigente sobre estos Derechos de Propiedad Industrial.

2. Se ha establecido la importancia del acto de registro de los bienes inmateriales para gozar y dar cabida a la protección penal de tales bienes inmateriales constituidos en Derechos de Propiedad Intelectual e Industrial.

3. Se ha presentado, por un lado, como principal motivación para el análisis de la tutela penal de la Propiedad Industrial el auge de las creaciones intelectuales en las actividades o actos de comercios de las empresas, y por otro lado, se ha determinado, como principal problemática en este entorno la creciente criminalidad por la utilización comercial ilícita, y fraudulenta de tales bienes inmateriales por parte de terceros que trae como consecuencia un perjuicio al titular registral a quien le corresponde la explotación exclusiva de su propiedad.

4. Del análisis del delito de Fraude sobre patente, modelo de utilidad o diseño industrial se ha logrado conocer de manera global la estructura del tipo y las conductas ilícitas en las que puede incurrir un tercero infractor, así como el castigo que le impone la norma jurídico penal.

5. Del estudio general de los elementos típicos comunes de todos los delitos relativos a la Propiedad Industrial se ha evidenciado que nos encontramos con delitos que presentan características similares que son perfectamente deducibles del propio precepto normativo.

6. En definitiva, el estudio muestra la protección de la Propiedad Industrial desde la norma jurídico penal sustantiva, como una herramienta a conocer y aplicar por los titulares de Derechos de Propiedad Industrial; mecanismo poco promovido en la práctica empresarial nicaragüense puesto que hasta la actualidad no existe la cultura de resolver conflictos de esta naturaleza en la vía jurisdiccional penal.

\section{Referencias}

Nicaragua, Asamblea Nacional (2000). Ley No. 354, Ley de Patentes de Invención, Modelo de utilidad y Diseños Industriales.

Nicaragua, Asamblea Nacional (2008). Ley No. 641, Código Penal.

Bendaña Guerrero, G. (1999). Curso de Derecho de Propiedad Industrial. Managua, Nicaragua: Hispamer. 
Canizalez Escorcia, M. (2016). Ley No. 641 Código penal Comentado, Concordado, Con Doctrina y Jurisprudencia. Managua, Nicaragua: Editorial SENICSA.

Díaz y García Conlledo, M. (2009). Delitos contra la propiedad intelectual e industrial. Madrid, España, pp. 93 -134.

Díaz, C., y Martínez, P. (2016). Apuntes Derecho Penal Parte General. León, Nicaragua, inédito.

Flores Paiz, J. (2019). Protección de la Propiedad Industrial, en el marco de la actividad empresarial a la luz de la legislación penal nicaragüense (Tesis de maestría). Universidad Nacional Autónoma de Nicaragua UNAN, León.

Luzón Peña, D. (2017). Lecciones de Derecho Penal. Parte General (3 ed.). Managua, Nicaragua: Facultad de Ciencias Jurídicas UCA.

Mapelli Caffarena, B. (2001). Consideraciones en torno a los delitos contra la Propiedad Industrial. Derecho y conocimiento: anuario jurídico sobre la sociedad de la información y del conocimiento, ISSN 1578-8202, (No. 1), pp. 111-132.

Mestre Delgado, E. (2016). "Tema 13. Delitos contra el patrimonio y contra el orden socioeconómico", en Carmen, Lamarca Pérez (Coord.), Delitos. La parte especial del derecho penal ( p. 464-486 ). Madrid, España: Dykinson.

Muñoz Conde, F. (2017). Derecho Penal, Parte Especial (21 ed.). Valencia, España: Tirant Lo Blanch.

Orts, E., y González, J. (2004). Manual de Derecho Penal. Parte General. España: Proyecto de Reforma y Modernización normativa CAJ/FIUUSAID.

Real Academia Española. (2019). Diccionario de la lengua española (versión electrónica). Madrid, Espana: Real Academia espanola., https://www.rae.es/.

Rodriguez Fernandez, R. (2008). La protección penal de los derechos de propiedad industrial, Diario La Ley, ISSN 1989-6913, (No 7033), p.4.

Serrano, A., Serrano, A., Serrano, M., Vázquez, C. (2016). Curso de Derecho Penal, Parte Especial (3 ed.). Madrid, España: Dykinson.

Sherwood, R. (1995). Propiedad Intelectual y Desarrollo Económico. Buenos Aires, Argentina: Heliasta.

Viñamata Paschkes, C. (2007). La Propiedad Intelectual (4 ed.). México, D.F: Trilla 